\title{
Advocating for pregnant women in prison: Georgia can do better
}

\author{
Nancy Webb, $\mathrm{PhD}^{1}$ and Madison Gates, $\mathrm{PhD}^{2}$ \\ ${ }^{1}$ Division Chief, Education and Program Development, Institute of Public and Preventive Health; Director, Child Care Center; and Professor of \\ Pediatrics and Graduate Studies, Georgia Regents University, Augusta, GA; and ${ }^{2}$ Assistant Professor, Institute of Public and Preventive Health, \\ Georgia Regents University, Augusta, GA
}

\begin{abstract}
Background: Women are the fastest growing segment of the U.S. prison populace and approximately 1 in 25 were pregnant when they were incarcerated. However, women, including pregnant women, are receiving unacceptable health care in correctional systems. Further, many correctional systems lack policies to protect the best interest of incarcerated women, mothers and their children.

Methods: We reviewed the literature on pregnant women in prison and found that corrections has been slow in making changes and adapting facilities for women, especially related to pregnancy, parenting skills and nurseries. It has been suggested the parent-infant attachment and the involvement incarcerated parents have with their children can help in preventing intergenerational crime.

Results: The prison system in the U.S. is not set up to meet the needs of pregnant women prisoners. Many states, including Georgia, do not have policies regarding prenatal care or the use of restraints during labor and delivery.

Conclusions: Georgia should rethink its prison-spending model. It would behoove Georgia's leaders to take a look at what programs exist for pregnant women and mothers and consider adopting a model that would be a good fit for our state. We propose a collaborative approach for stakeholders to improve the care of pregnant offenders and the health of their children.
\end{abstract}

Key Words: Incarcerated pregnant women, mothers and children behind bars, child care in prisons

\section{INTRODUCTION}

In the U.S., approximately 1.6 million children have mothers serving time for various crimes (Hartney, 2007). In 1995, women comprised $6.1 \%$ of the total number of prisoners in the country; in 2005, that number increased to $7.0 \%$ (Hartney, 2007). Unfortunately, the policies for incarcerated pregnant women and mothers do not necessarily protect the best interest of mothers and their children. They also do not always protect the civil and human rights of the mothers and children. Women are the fastest growing segment of the U.S. prison populace and, according to the Marshall Project, approximately 1 in 25 of the 98,000 female inmates in U.S. state institutions were pregnant when they were incarcerated (Stewart, Duffey, Cassid, Kennedy, \& Haines, 2008). For this population, many states do not have policies regarding prenatal care, the use of restraints, alternatives to incarceration, and childcare that allow children to stay with their imprisoned mothers (Saar, 2010).

In 2009, the National Association of Women Judges disclosed that women, including pregnant women, in federal prisons were receiving unacceptable health care (Saar, 2010). The Federal Bureau of Prisons (BOP) has developed policies that exclude routine use of restraints during labor and delivery ("Facts," 2014). However, information is lacking regarding the implementation of this policy (Saar,
2010). Further, only 21 states have passed similar laws ("Facts," 2014). Georgia is not one of those states.

The State of Georgia has the fifth largest prison population in the country and houses the fourth largest female population (Hartney, 2007). Georgia spends over one billion dollars annually to operate its prison system (Teegardin, 2010). Further, Georgia is third in the nation for states with the highest rates of involvement in corrections by women and girls (Hartney, 2007). In reference to Georgia's corrections system, Georgia's governor recently stated: "If current policies remain in place, analysis indicates that Georgia's prison population will rise by another 8 percent to reach nearly 60,000 inmates by 2016 , presenting the state with the need to spend an additional \$264 million to expand capacity" (Stirgus, 2012). The purpose of this paper is to generate discussions, especially in Georgia, about the pregnant female prison population and about ways to improve the system to make Georgia a model for U.S. prisons to emulate.

\section{Imprisoned Pregnant Women Have Special Needs}

The prison system in the U.S. is not set up to meet the needs of pregnant women prisoners. Incarcerated women, compared to men, are much more likely to have mental and behavioral health issues that often can be attributed to a history of trauma or exposure to violence (Woodson, Hives, \& Sanders-Phillips, 2010). Incarceration of women 
also exacerbates their problems, since prisons were designed for men, who historically have populated correctional facilities (Soler, 2009). Despite having evidence regarding women's health issues, correctional facilities have been slow in making changes and adapting facilities for women. The mission of correctional systems is often stated as that they provide public safety, rehabilitation, and health care, but the current environment of combating crime tends to result in a tilt more toward the punitive and public safety roles (Gardner, 2012; Miller, 2014; Soler, 2009) than social and rehabilitative services.

The federal BOP does not operate any nurseries in prisons (Saar, 2010); however, eight states have implemented nursery programs for imprisoned mothers (DeBoer, 2012). These programs are essential if mothers and their infants are to develop a secure attachment. While the federal BOP has policies for screening inmates for pregnancy and providing them with medical and social services support ("Female Offenders," 2015), access to prenatal care is inconsistent (Saar, 2010). The BOP also has policies on providing services related to pregnancy, birth control, and abortion and makes arrangements for child placement ("Female Offenders," 2015). It also provides policies on offering preand post-natal classes on parenting and related topics ("Female Offenders," 2015). Consistent implementation of these services and this approach to incarcerated mothers are appropriate since the family is viewed as the best environment for raising a child (Wolleswindel, 2002).

A study conducted in 2009 questioned wardens of women's prisons in the U.S. The findings indicate that, in many facilities, pregnant women were not receiving adequate nutrition, were not provided extra rest periods, did not receive work accommodations, and were subjected to the use of restraints, and, in some cases, restraints were used during labor and delivery (Ferszt \& Vang, 2015). These authors also found a scarcity of counseling, parenting education, support groups, and education on pregnancy and delivery (Ferszt \& Vang, 2015). These programs are necessary in preventing premature birth and low-birthweight babies and are instrumental in ensuring the child's and the mother's emotional, physical, and intellectual development during a critical period. Programs for pregnant prisoners can reduce the chances that these babies will later enter the criminal justice system, which results in a significant savings (Saar, 2010). Thus, these incarcerated women and their unborn children should not have to endure these adverse conditions. They deserve prenatal and postnatal care and education, appropriate nutrition, the right to deliver without the use of restraints, and opportunities to care for their infants so that the attachments become healthy ones.

\section{The Early Years are the Formative Years}

Effective parenting practices and family relationships can enhance the deterrence of wrongdoing (Hairston, 2001). On the other hand, there is a relationship between the absence of parental involvement, attachment, and rejection to delinquency (Larzelere \& Patterson, 1990). The parentinfant attachment and the involvement incarcerated parents have with their children can help in preventing intergenerational crime (Hairston, 2001). There is evidence that parental problems and detachment lead to adolescent delinquency, particularly for females (Mulder, Brand, Bullens, \& van Marle, 2011; Walters, 2013; Woessner \& Schneider, 2013). Another study found direct and indirect associations between maternal incarceration, prenatal care, and adolescent involvement with the juvenile justice system (Shlafer, Poehlmann, \& Donelan-McCall, 2012).

The family histories of Georgia offenders appear to support the relationship between the early years and incarceration. In 2013, the Georgia Department of Corrections (GDC) reported that only $39 \%$ of men and $30.5 \%$ of women indicated that they had both parents in their life when they were 16 years old. Absent mothers were reported by $12.3 \%$ of men and $13.3 \%$ of women; the GDC did not collect data in regard to the reasons for absent mothers. An alarming $21.1 \%$ of men and $38.4 \%$ of women reported that a family member had a history of incarceration. Although there are other factors associated with correctional involvement, these data suggest that parental involvement is an important consideration for intergenerational crime.

Attachment is a process that occurs between mothers and their babies. It takes place during the first year of life as parents interact with their infants. Such attachments predict the child's emotional and social development as well as his/her ability to form positive relationships with others throughout life. Attachment theory is one of the most widely held and research-grounded theories relating to parenting (Benoit, 2004). Attachments can be secure or insecure (Byrne \& Benning, 2015). Insecure attachments can be categorized as avoidant, resistant, or disorganized (Benoit, 2004). Infants who have mothers who respond lovingly and sensitively to their various cries and needs during the first year of life generally develop secure attachments. These babies learn to trust that their needs will be met. They tend to thrive and go on to develop healthy relationships with others. On the other hand, infants who have mothers who are not responsive to their needs or who reject them or show insensitivity are more likely to develop insecure attachments. These babies will learn to avoid the parent. This pattern of insecure attachment most likely results in a child who develops issues such as social and emotional maladjustment (Benoit, 2004).

There is evidence that it is possible to raise a child with a healthy attachment in prison. Byrne studied 97 mothers and 100 infants in a New York correctional facility. Mothers were randomly assigned to a child health treatment group or a mother-child relationship group. She found that the propensity of raising a child with a healthy attachment was more likely in the mother-child relationship group (Byrne, 2010). However, mothers in each intervention group depicted more responsiveness toward their children, a better understanding of good childcare, raised levels of sensitivity, and a feeling of knowing how to parent.

\section{Change is Needed}

We believe that correctional facilities have an obligation to improve conditions for pregnant women and mothers. In Europe, it is not unusual for imprisoned mothers to keep 
their children with them. It is time for Georgia to rethink its model for prison spending. At present, there are only nine U.S. prison nurseries within criminal justice facilities (Byrne \& Benning, 2015). We can do better. For example, the National Institute of Corrections has pointed out that the Washington Correction Center for Women has developed a prison childcare program coalescing an Early Head Start and a residential parenting program ("Residential Parenting Program," 2009). It would behoove Georgia's leaders to take a look at what programs exist for pregnant women and mothers and consider adopting a model that would be a good fit for our state. A good resource and place to begin reviewing models is The Rebecca Project for Human Rights (Saar, 2010). After all, "If a community values its children, it must cherish their parents" (Bowlby, 1951).

We recognize the competing missions to provide for public safety and to prepare offenders to reenter the free world. We also understand that correctional facilities have tight

\section{References}

Benoit, D. (2004). Infant-parent attachment: Definition, types, antecedents, measurement and outcome. Paediatr Child Health, $9(8), 541-545$.

Bowlby, J. (1951). Maternal care and mental health. Geneva,: World Health Organization.

Byrne, M. W. (2010). Interventions within Prison Nurseries. In M. J. Eddy \& J. Poehlmann (Eds.), Children of Incarcerated Parents: A Handbook for Researchers and Practitioners: Urban Institute Press. $2100 \mathrm{M}$ Street NW.

Byrne, M. W., \& Benning, S. (2015, Winter). Prison Nursery Coresidence and Re-entry: New York Studies. Healthy Generations.

DeBoer, H. (2012, March 30). Prison Nursery Programs in Other States. Retrieved 2015, April 20, from http://www.cga.ct.gov/2012/rpt/2012-R-0157.htm

Facts. (2014). Birthing Behind Bars. Retrieved 2015, April 20, from http://nationinside.org/campaign/birthing-behindbars/facts /

Female Offenders. (2015). Retrieved 2015, April 20, from http://www.bop.gov/inmates/custody_and_care/female_off enders.jsp

Ferszt, G., \& Vang, S. (2015, Winter). A National Survey of Women's Correctional Facilities: Health Care for Pregnant Incarcerated Women. Healthy Generations.

Gardner, M. R. (2012). Punitive Juvenile Justice and Public Trials by Jury: Sixth Amendment Applications in a Post-McKeiver World. Nebraska Law Review, 91, 1.

Hairston, C. F. (2001). Prisoners and Families: Parenting Issues During Incarceration. Paper presented at the From Prison to Home: The Effect of Incarceration and Reentry on Children, Families, and Communities, Bethesda, MD.

Hartney, C. (2007, July). The Nation's Most Punitive States for Women National Council on Crime and Delinquency.

Larzelere, R. E., \& Patterson, G. R. (1990). Parental Management: Mediator of the Effect of Socioeconomic Status on Early Delinquency. Criminology, 28(2), 301-324. doi: 10.1111/j.17459125.1990.tb01327.x

Miller, L. (2014). Juvenile crime and juvenile justice: Patterns, models, and implications for clinical and legal practice. Aggression and Violent Behavior, 19, 122-137. doi: 10.1016/j.avb.2014.01.005

Mulder, E., Brand, E., Bullens, R., \& van Marle, H. (2011). Risk factors for overall recidivism and severity of recidivism in budgets, do not legislate what is criminal, and do not adjudicate crimes. However, there are areas where corrections can have an influence, such as recognizing and accommodating the health needs of women offenders. We recommend that correctional facilities link health needs of women to reentry efforts to include parental involvement and parenting programs. We also suggest improving mental health support, health care, and programs to interrupt the cycle of inter-generational incarceration. There is evidence that children of incarcerated parents are harmed long-term as a result of parental detachment and poor parenting skills (Shlafer et al., 2012). Such reentry programs may have long-term value not only for offending adults, but also for their children. These changes may necessitate policy changes and an investment in resources. We also recommend further studies that investigate the effect that incarceration has on children, particularly girls, to determine the extent, type, and seriousness of recidivism.

serious juvenile offenders. Int J Offender Ther Comp Criminol, 55(1), 118-135. doi: 10.1177/0306624x09356683

Residential Parenting Program. (2009). Retrieved 2015, April 15, from http://nicic.gov/wodp/?View=Program\&P=363

Saar, M. (2010). Mothers Behind Bars: A state-by-state report card and analysis of federal policies on conditions of confinement for pregnant and parenting women and the effect on their children. Washington, DC: The National Women's Law Center.

Shlafer, R. J., Poehlmann, J., \& Donelan-McCall, N. (2012). Maternal jail time, conviction, and arrest as predictors of children's 15-year antisocial outcomes in the context of a nurse home visiting program. J Clin Child Adolesc Psychol, 41(1), 3852. doi: 10.1080/15374416.2012.632345

Soler, M. (2009). Juvenile Justice: Lessons For A New Era. Georgetown Journal on Poverty Law \& Policy, 16, 483.

Stewart, J., Duffey, S., Cassid, L. A., Kennedy, K., \& Haines, S. (2008) In Ohio, Inmate Mothers Care For Babies In Prison/Interviewer: S. Inskeep \& R. Montagne. National Public Radio.

Stirgus, E. (2012, January 25). Deal makes arresting claim about Georgia prisons. Atlanta Journal Consitution. Retrieved from http://www.politifact.com/georgia/statements/2012/jan/2 5/nathan-deal/deal-makes-arresting-claim-about-gaprisons/

Teegardin, C. (2010, April 07). Georgia prison population, costs on rise. Atlanta Journal Constitution. Retrieved from http://www.ajc.com/news/news/local/georgia-prisonpopulation-costs-on-rise/nQdsN/

Walters, G. D. (2013). Delinquency, parental involvement, early adult criminality, and sex: Evidence of moderated mediation. J Adolesc, 36(4), 777-785. doi: 10.1016/j.adolescence.2013.03.011

Woessner, G., \& Schneider, S. (2013). The role of self-control and self-esteem and the impact of early risk factors among violent offenders. Crim Behav Ment Health, 23(2), 99-112. doi: $10.1002 / \mathrm{cbm} .1863$

Wolleswindel, R. (2002). Children of Imprisoned Parents. In J. C. M. Willems (Ed.), Developmental and Autonomy Rights of Children: Empowering Children, Caregivers and Communities (pp. 191 - 207): Intersentia.

Woodson, K. M., Hives, C. C., \& Sanders-Phillips, K. (2010). Violence Exposure and Health-Related Risk Among African American Adolescent Female Detainees: A Strategy for Reducing Recidivism. Journal of Offender Rehabilitation, 49(8), 571-594. doi: 10.1080/10509674.2010.519669 